\title{
EFFECTS ANALYSIS OF THE POLLUTION LAYER PARAMETERS ON A HIGH- VOLTAGE PORCELAIN CYLINDRICAL INSULATOR USING RESPONSE SURFACE METHODOLOGY
}

\author{
Khaled BELHOUCHET ${ }^{1 *}$, Abdelhafid BAYADI ${ }^{2}$, Nadjim ALTI ${ }^{2}$, Lyamine OUCHEN ${ }^{2}$ \\ ${ }^{1}$ Department of Electrical Engineering, Faculty of Technology, Mohamed Boudiaf University, \\ M'sila 28000, Algeria. \\ ${ }^{2}$ Department of Electrical Engineering, Faculty of Technology, Ferhat Abbas University, \\ Setif - 1, 19000, Algeria \\ *khaled.belhouchet@univ-msila.dz, ___bayadi@yahoo.fr, alti.nadjim@yahoo.fr, \\ amine.ouchen@yahoo.fr
}

\begin{abstract}
The influences of the pollution layer parameters including; conductivity, position and length on the performance of high-voltage cylindrical insulator were investigated. Parameters effects and their interactions have been assessed and determined using the variance statistical technique and the relation between parameters and the flashover voltage, maximum electric field and the breakdown strength is modeled by the response surface methodology (RMS). The 3D model from Comsol Multiphysics was used for modeling and the FEM method was utilized for simulations. The findings demonstrate that the flashover voltage of the non-uniformly contaminated surface is primarily affected by the pollution layer length. Simulation results show that the intensity of the electric field rises with the increasing in length of pollution layer and its position. It was noted that the experimental tests in laboratory for non-uniform contamination are in strong alignment with simulation studies. The results of this analysis should expand our understanding about the performance of outdoor insulators under specific contaminated conditions. The knowledge gathered can be used to enhance the configuration of insulators used in contaminated regions and it is believed that the current study has resulted methodology to estimate reliably and realistically the pollution performance of cylindrical porcelain insulators.
\end{abstract}

Keywords: insulators, electric field, finite element method, pollution, response surface methodology.

\section{INTRODUCTION}

Nowadays, the reliability of power system is related essentially to the good performance of high voltage outdoor insulators and its ability to work under all environmental conditions. The deposition of pollution on the insulator surface is one of the factors that reduce significantly its performance and can cause flashover. With the increasing voltage of transmission lines, the value of work on insulator emissions has been significantly increased. At the other side, the flashover of contaminated insulators will trigger a long-lasting transmission line blackout over a wide region. Flashover of contaminated insulators appears to pose a significant danger to the secure functioning of the electricity transmission grid [1]. Pollution flashover is commonly deemed increasingly significant in the construction of high voltage transmission lines. For this reason, the insulators must be designed so that the dielectric strength remains high enough to withstand all types of voltage stresses expected in the presence of pollution. Except in certain situations where pollution is very serious, other preventive or curative measures such as washing or periodic lubrication become more important [2-4]. In general, the distribution of pollution on the surface of the insulators is not uniform. Indeed, electro-geometric and climatic conditions play an important role in the accumulation and distribution of pollution on the surface of an insulator. In order to better study the behavior of insulators under several forms of pollution, different laboratory models have been proposed to avoid the difficulty linked to the complex shape of the insulator by simple geometry models. The flashover of the surface of contaminated insulators is affected by previous parameters such as; the insulator profile, insulator diameter, voltage distribution, nonuniform pollution [4]. Insulator pollution work is primarily aimed at understanding the dynamics of discharge production, and creating a mathematical 
model that can reliably predict critical current and flashover voltage. The past investigations carried out to address this problem may be grouped as natural testing, laboratory testing of polluted insulators, prediction of pollution flashover of insulators using intelligent systems and mathematical models. The intelligent systems such as artificial neural network (ANN) have been used in predicting the pollution flashover voltages [1]. The description of the propagating arc comprising of a partial arc in series of unabridged portion of the polluted layer resistance is a common characteristic of the mathematical models proposed by researchers [5- 8]. Taking into account the effects of different physical parameters, Alston [7] and Wilkins [8] suggested mathematical models for the prediction of critical flashover voltage. In [5-7] researchers have studied the Influence of the pollution Layer on the Insulator Flashover. Reported result show that the severity of pollution, the configuration of pollution and the voltage polarity affect simultaneously the flashover. In [6, 8], authors studied the effect of non-uniform pollution distribution on the insulators performance. They found that the flashover voltage in the case of non-uniform transversal distribution polluted insulators is higher compared with that obtained by uniform contamination and the flashover voltage value decreases linearly with increasing of the polluted layer width.

In this paper, an experimental study about a cylindrical porcelain insulator is proposed to investigate the effect of pollution layer parameters such as; length, position and conductivity on its performance. The use of statistical models to treat the relation between outdoor insulator and the pollution layer parameters becomes very interesting. For this, the variance statistical technique (ANOVA) is used to assess the impact of each parameter. The pollution layer position, Conductivity and length were varied in this research. The Relationship between the surface flashover, maximum electric field and breakdown strength and the chosen parameters is modeled by the response surface methodology (RMS). The result of this study can provide more information and further our knowledge about the performance of outdoor insulators in the polluted area.

\section{TEST OBJECT AND EXPERIMENTAL PROCEDURE}

\subsection{Simple preparation}

The studied simples are prepared from the mixture of kaolin, quartz, feldspar, and recycled waste glass. Fig. 1 shows the forms of the studied samples. The details of the manufacturing steps of porcelain samples, also the microstructure characterization, Hardness measurement and its dielectric properties are studied and detailed in a previous study [9].

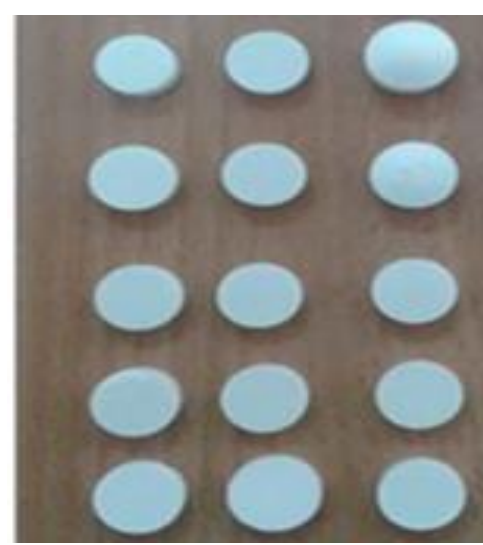

Fig. 1. The studied samples

The experimental study is realized in the high voltage laboratory of Technical University of Catalonia (UPC), Spain. Disc specimens of $20 \mathrm{~mm}$ diameter and $5 \mathrm{~mm}$ thickness and $150 \mathrm{~mm}$ as a total length were tested. The main geometric parameters are shown in Fig. 2.

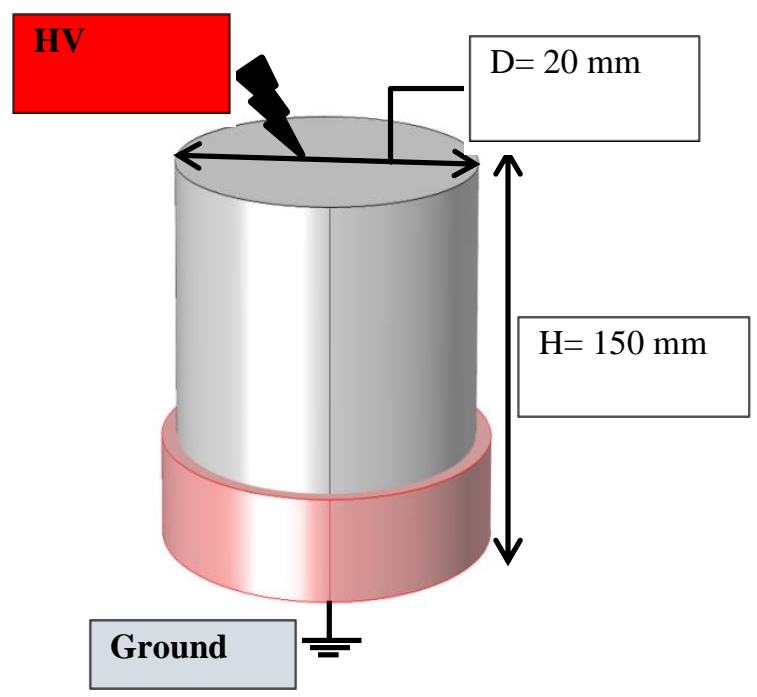

Fig. 2. The tested sample of porcelain cylindrical insulator. (H: Structure height of the cylindrical insulator, D: Diameter of the cylindrical insulator)

Pollution layer was prepared in the laboratory using $\mathrm{NaCl}$ and distilled water. The tested conductivities were: 10, 50 and $80 \mathrm{mS} / \mathrm{cm}$. Similarly, three thickness values of pollution layer were chosen; 4,8 and $12 \mathrm{~mm}$. The position of pollution layer was varied between: Ground $(\mathrm{G})$, Middle (M) and HV (H).

Measurement circuit of the flashover voltage is shown in Fig.3. It is composed of a high-voltage transformer $\mathrm{Tr}$, which delivers a maximum voltage of $(120 \mathrm{kV})$. This circuit is rectified by a diode D and is smoothed by a condenser C. A sample is connected at the boundaries of the protection resistance $\mathrm{Ra}$ and at the resistive voltage divider $(\mathrm{R} 0, \mathrm{Ru})$. The voltage of each test is read directly on a digital crest voltmeter (V).The maximum speed of the slope of the voltage is fixed at (4 $\mathrm{kV} / \mathrm{s}$ ). The selection of this value was made to 
prevent the partial draining of the pollution's layer deposited on the material surface during the variation of the test's applied voltage. The visualization of the parallel electric discharges is performed by a fast camera (Cam). This research uses experimental tests for three scenarios taking into account the different values of the three chosen parameters.

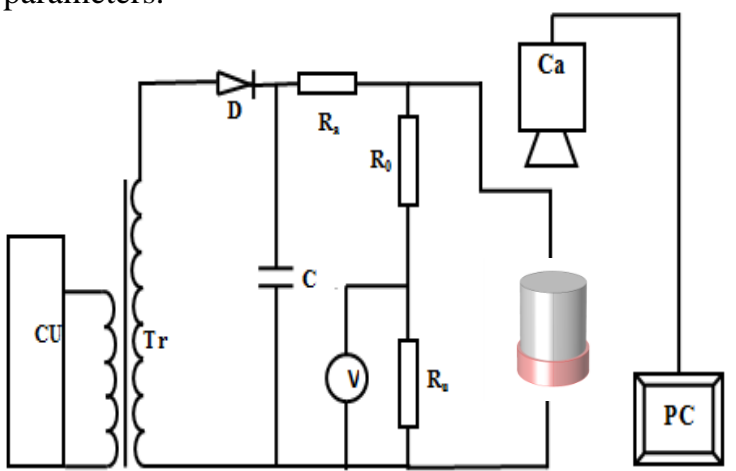

Fig. 3. Overall view of Experimental setup.

The studied model was tested under DC voltage. The applied voltage was increased using constant speed of the slope until the flashover occurs as shown in fig. 4. This process was repeated for all studied configurations.It can be obtained from fig. 4 that, under non-uniform pollution most of the partial discharges occur and the main arc, which develops into the flashover.

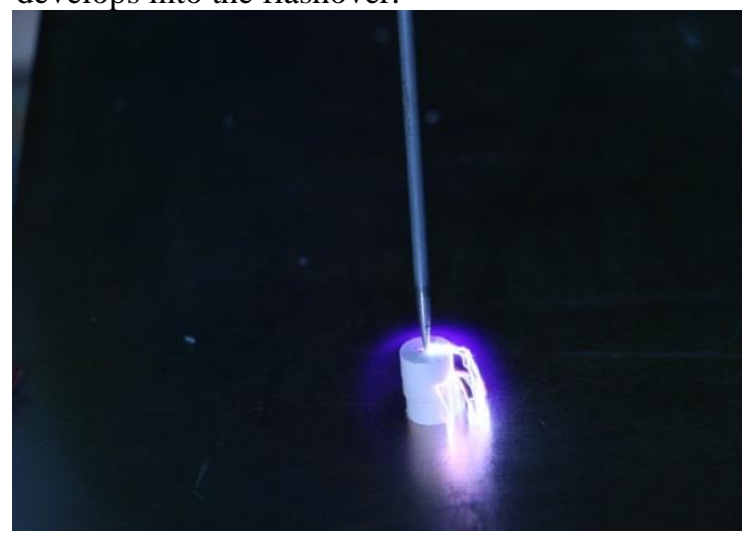

Fig. 4. Studied insulator model.

In order to quantify the influence of the nonuniform pollution layer on the distribution of electric fields, 3D models represent all the considered configurations were modeled and analyzed using COMSOL Multiphysics $₫$ software. Electrical tests were conducted in order to understand the impact of the interaction between the various pollution layer parameters and Taguchi orthogonal array (L9 OA) experimental design was created to determine the minimum number of tests. It is one of the most powerful methods for the optimization of multifactor conditions. Under the studied conditions of removal, it is used to achieve the best response. Furthermore, the experimental method is designed to enable independent evaluation of variables through a limited number of trials. In this study, L9 OA was used to test the impact of the studied parameters of the nonuniform pollution layer on the flashover voltage, the maximum electric field and the breakdown strength. The studied parameters of non-uniform pollution and their levels are indicated in Table1. The experimental results and combination of the parameters at different levels is shown in Table 2.

Table1. Non-uniform pollution parameters and their

\begin{tabular}{llllc} 
& & \multicolumn{4}{c}{ studied levels. } \\
\hline Parameters & Code & \multicolumn{2}{l}{ variation ranges } \\
\hline $\begin{array}{l}\text { Conductivity } \\
\text { mS/cm }\end{array}$ & $\mathrm{C}$ & 10 & 50 & 80 \\
$\begin{array}{l}\text { Layer length } \\
\text { (mm) }\end{array}$ & $\mathrm{L}$ & 4 & 8 & 12 \\
Position & $\mathrm{P}$ & $\begin{array}{l}\text { Ground } \\
(\mathrm{G})\end{array}$ & $\begin{array}{l}\text { Middle } \\
(\mathrm{M})\end{array}$ & $\begin{array}{l}\mathrm{HV} \\
(\mathrm{H})\end{array}$ \\
\hline
\end{tabular}

In this work, the MINITAB ${ }^{\circledR}$ software with $\mathrm{COMSOL}^{\circledR}$ was used. Statistical analysis using ANOVA has been executed to study the impact non-uniform pollution layer on the flashover strength, maximum electric field and the breakdown strength of the insulator surface. The analysis of the obtained response considers the effects of the factors and their interactions. A quadratic model -of flashover voltage in the case of non-uniform pollution- by regression was established and given by the following form:

$$
Y=a_{0}+\sum_{i=1}^{3} \mathrm{a}_{i} \mathrm{X}_{i}+\sum_{i=1}^{3} \mathrm{a}_{i i} \mathrm{X}_{i}^{2}+\sum_{i<j}^{3} a_{i j} X_{i} X_{j}
$$

Y: the desired response, $a_{0}$ : constant. $a_{i}, a_{i i}$ and $a_{i j}$ are the coefficients of linear, quadratic and crossproduct terms, respectively. $\mathrm{X}_{\mathrm{i}}$ is the coded factors that are related to the considered parameters.

Table 2. Computational results

\begin{tabular}{cccccc}
\hline Length & $\begin{array}{c}\text { Conductivity } \\
(\mathrm{mS} / \mathrm{cm})\end{array}$ & Position & $\begin{array}{c}\text { Flashover voltage } \\
(\mathrm{kV})\end{array}$ & $\begin{array}{c}\text { E-field }(\mathrm{kV} / \mathrm{cm}) \\
\begin{array}{c}\text { Breakdown } \\
\text { strength }(\mathrm{kV} / \mathrm{cm})\end{array}\end{array}$ \\
\hline 4 & 10 & HV & 23,20 & 9,60 & 19,5 \\
4 & 50 & Centre & 22,20 & 8,97 & 16,2 \\
4 & 80 & Ground & 21,50 & 9,49 & 17,3 \\
8 & 10 & HV & 19,02 & 11,62 & 17,2 \\
8 & 50 & Centre & 18,55 & 10,90 & 16,5 \\
8 & 80 & Ground & 17,20 & 11,40 & 15,4 \\
12 & 10 & HV & 16,80 & 12,80 & 14,1 \\
12 & 50 & Centre & 18,22 & 11,30 & 12,8 \\
12 & 80 & Ground & 17,60 & 13,20 & 11,2 \\
\hline
\end{tabular}




\section{RESULTS AND DISCUSSION}

Flashover voltage, maximum electric field and the breakdown strength are interested in this part; in which the effect of conductivity, pollution layer length and its position is presented. Statistical analysis using ANOVA has been executed to evaluate the result of the designed L9 OA. Response analysis from the RSM takes into account all parameters effects and their interaction is considered.

The main effects of polluted layer parameters on the flashover voltage are plotted and presented in fig. (5.a). It can be clearly seen that the flashover voltage is strongly affected by pollution layer length. The pollution layer length has a decreasing effect on the dielectric strength. It can be explained by the reduction of the clean band width. For lower applied voltage, the E- field applied on these bands increases and reaches the breakdown strength by consequence reduction of the flashover strength. Electrically, the reduction of the total equivalent impedance of the insulator model proportionally to the increase of the length of the conductive layer can explain this phenomenon.

Also, pollution layer conductivity affect the flashover by a decreasing impact. It is know that the dielectric strength of the surface of insulators is enhanced by decreasing pollution conductivity. From the same figure, flashover voltage dependent on pollution layer position as well as length and conductivity. It is shown that the flashover strength is the higher when the layer is located in middle position and energized end than the case of layer near the ground ends. It can be concluded that the highest dielectric strength of an insulating model is observed in the case of a smaller conductive layer lies in the middle.

From the interaction effect plots in fig. (5.b) a slight interaction effect between position and length occurs in which the lines are not parallel. When the length of pollution layer increase until $80 \mathrm{~mm}$, this effect becomes ignored. It can be explained by the significant decrease in clean band length.

Fig. 6 shows the normal probability plot of flashover voltage at $95 \%$ of confidence interval. It can be observed that a straight line of data is followed. In this study, the P-value is registered at 0.183 . This value is higher than alpha 0.05 . For this, the null hypothesis cannot be rejected. The null hypothesis is that the distribution of data law is normal. Therefore, the proposed model is adequate.

The main interaction effect plots of the three studied parameters (conductivity, pollution layer length and its position) on the maximum electric field is shown in fig.7. It is found that the maximum electric field value greatly increases when the length of the pollution layer increases. This observation is registered because the clean band is limited and becomes the only area that supports the maximum E-field. Pollution layer position has a significant effect on the maximum electric field value as well as the pollution layer length. It is clearly seen that the maximum E- field takes its higher value when the pollution layer lies near the energized and ground ends. On the other hand, when the pollution layer is situated in the middle, the electric field takes its lowest value. Because of its ignored impact on the redistribution of the electric potential, Conductivity has not a remarkable effect on the maximum E-field value. a)

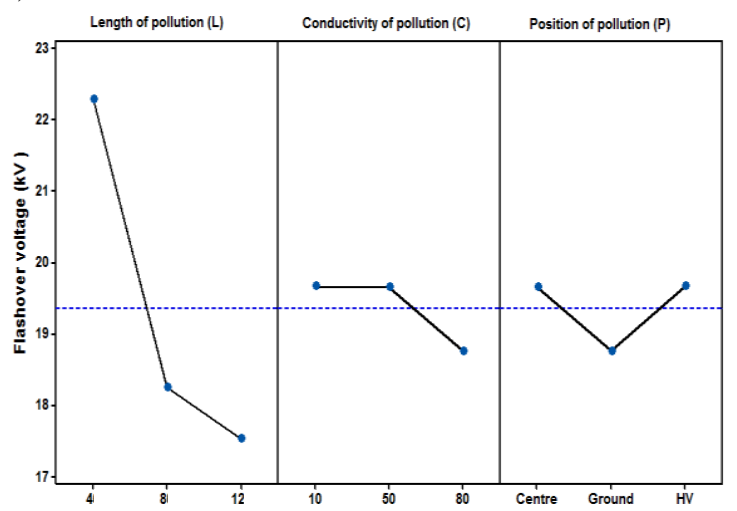

b)

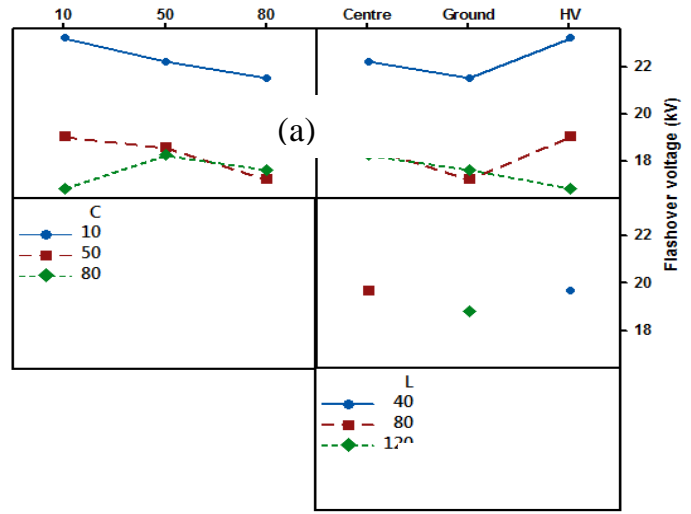

Fig. 5. Main effect plots of the pollution layer parameters on flashover voltage.

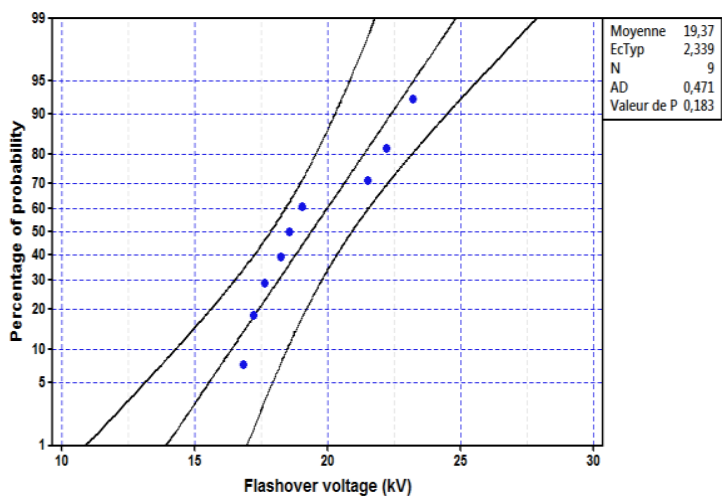

Fig. 6. Normal probability plot of flashover voltage at $95 \%$ of confidence interval

It is well noticed by the plots intersection that the location of the pollution layer in the middle of the insulating surface leads to the reduction of the maximum E-field. This reduction can be explained by the two clean bands that lie near the ends.

Fig. 8 shows the normal probability plot of the predicted responses of maximum E-field values at 
$95 \%$ of confidence interval. As mentioned previously, it appears that a slight line is followed. The maximum electric field P-value is superior to alpha 0.05.in this case, null hypothesis cannot be denied so, the data follows anormaly distribution.

The effect of non-uniform pollution parameters on the breakdown strength is investigated and the main interaction effect plots on the breakdown strength are presented in fig 9. Conductivity pollution layer length and its position have an impact on the breakdown strength as well as flashover voltage and maximum electric field value. It appears that the breakdown strength decreases with increasing of both; conductivity and the pollution layer length. On the other hand, the breakdown strength decreases when the pollution layer is positioned in the middle and near the a)

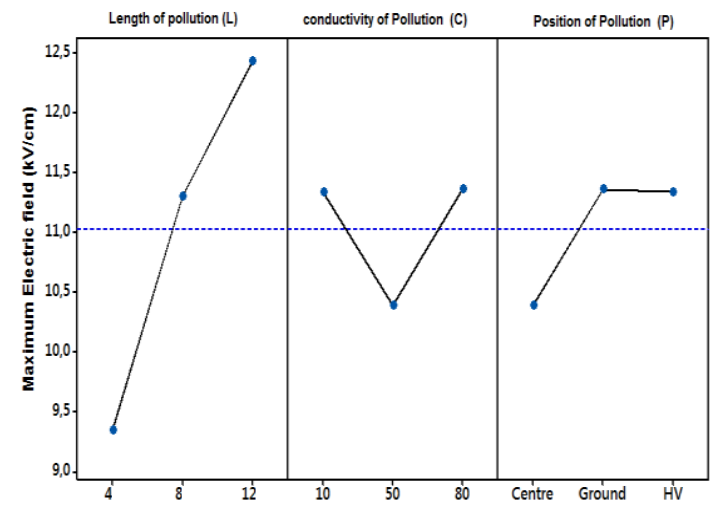

b)

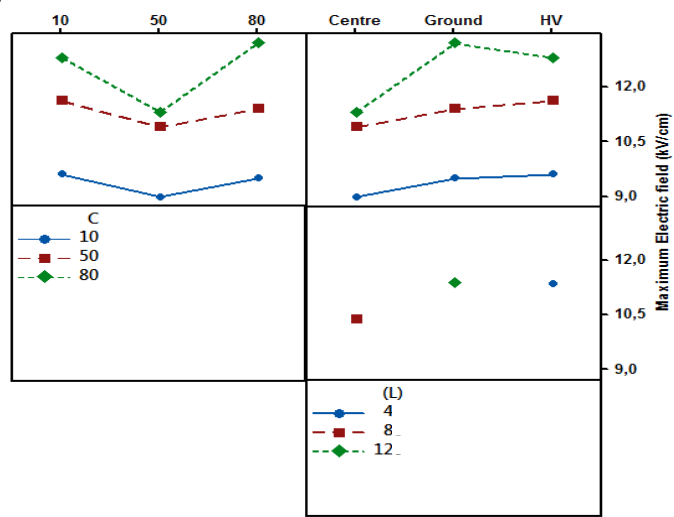

Fig. 7. Main effect plots of the pollution layer parameters on the maximum E-field.

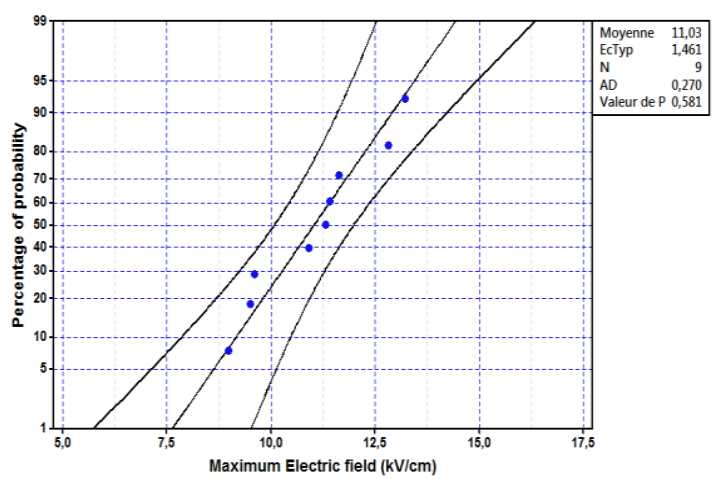

Fig. 8. Normal probability plot of the maximum E-field. at $95 \%$ of confidence interval ground end of the insulating model. The presence of the pollution layer near the energized end leads to increasing the breakdown strength. The increased conductivity of pollution layer leads to a higher amount of leakage current flow on the insulator surface.

The increase of the number of dry bands in the middle of insulator surface may cause an increasing impact on breakdown strength. On the other hand, when many dry bands are created near the two ends the electric field stress on the surface decreases. They present in this case a potential barrier that decreases the electric field intensity under low voltage.

Fig 10 shows the normal probability plot of the predicted responses of maximum E-field values at $95 \%$ of confidence interval. As mentioned previously, it appears that a slight line is followed. The maximum electric field P-value is superior to alpha 0.05.in this case, null hypothesis cannot be denied so, the data follows anormaly distribution.

The main advantage of the presented methodology is that it provides an interesting knowledge about the impact of the non -uniform pollution parameters on the flashover process and the dielectric behavior along ceramics insulators. The presented investigations can be an efficient tool to develop a suitable mathematical model for calculations under non-uniform pollution. Therefore, the results of this study could be useful for the design and selection of ceramic insulators for polluted area.

\section{SIMULATION RESULTS}

The study of electric field distribution along the surface of the insulator is very important to understand its flashover characteristics. The studied model of insulator is presented in fig. 2 it was simulated in Comsol Multiphysics as 3D geometry. Electric field distribution were plotted for all configurations. The equations governing the electric field computation in Comsol is given below [10].

$$
\begin{aligned}
& \nabla . J+Q_{j} \\
& J+\left(\sigma+j \omega \varepsilon_{0} \varepsilon_{r}+J_{e}\right) \\
& \nabla E=\frac{\rho}{\varepsilon} \\
& -\nabla(\nabla E)=\frac{\rho}{\varepsilon} \\
& \varepsilon \nabla(\nabla E)=0 \\
& J=\sigma E
\end{aligned}
$$

Where $\rho$ is the resistivity, $\varepsilon$ is the dielectric constant, $J$ is the current density and $\sigma$ is the conductivity of pollution layer

Electric field distribution along a porcelain cylindrical insulator was investigated under contamination conditions to assess the impact of pollution layer parameters on E- field stress along the insulator surface. Electric field distribution of all pollution configurations are shown in fig. 11 . 


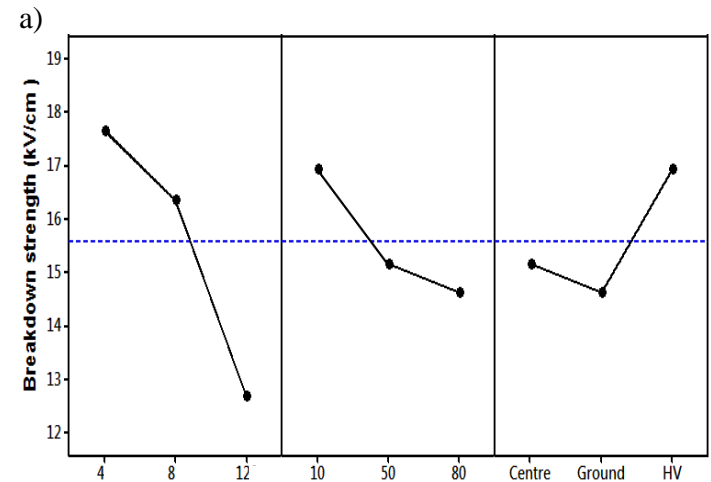

b)

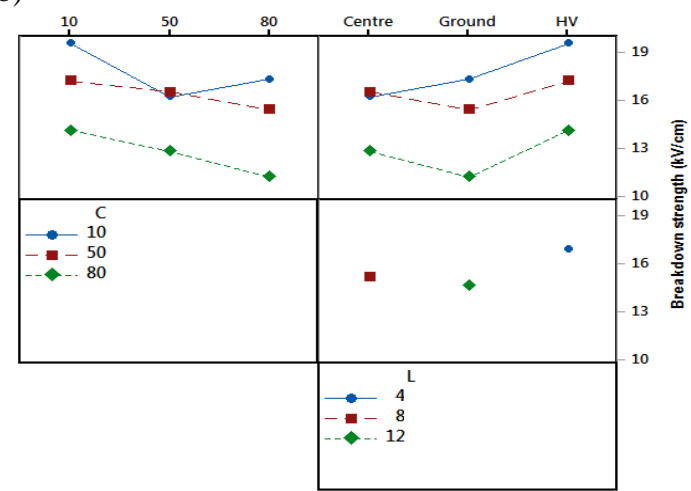

Fig. 9. Main effect plots of the pollution layer parameters on breakdown strength

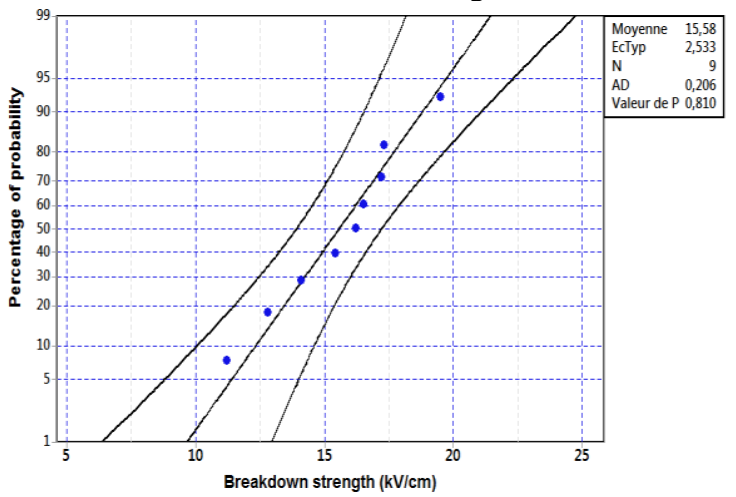

Fig. 10. Normal probability plot of breakdown strength at $95 \%$ of confidence interval

It was observed during simulations that pollution layer length and position change the electric field distributions along the insulator surface as shown in figs 12 and 14 respectively. This trend was more evident in the case of changes in layer length and position as compared to conductivity. As the pollution layer length was changed from 4 to $12 \mathrm{~mm}$, the E-field increases from 4 to $18 \mathrm{kV} / \mathrm{cm}$ as shown in Figs. 12 and 13. Conductivity of the pollution layer was kept constant at $50 \mathrm{mS} / \mathrm{cm}$ for all cases. Also, pollution layer position was kept constant at the energized end for this case. Although conductivity of the pollution layer is same, but increase in layer length and changing position lead to increase in current density and subsequently electric field. a)

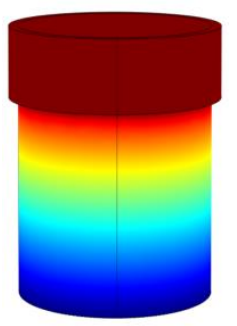

$\mathrm{C}=50 \mathrm{mS} / \mathrm{cm}$

b)
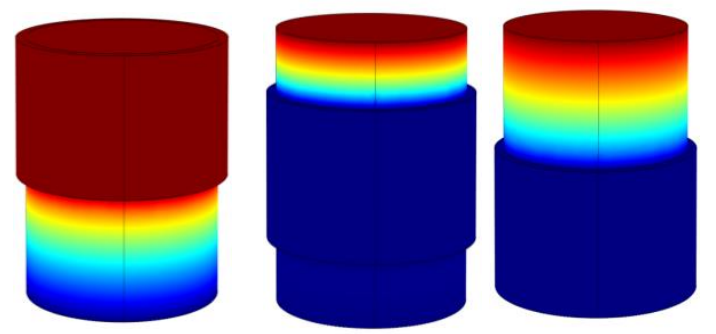

c)

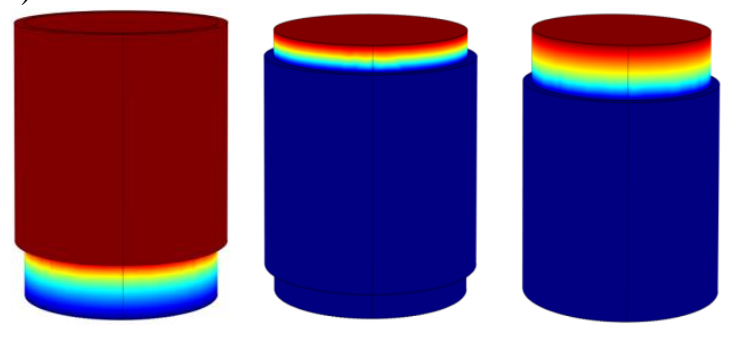

Fig. 11. Electric field distribution along a non-uniformly polluted insulator: (a) non uniform layer of $4 \mathrm{~mm}$ near ground end, near energized end and in the middle of insulator model, (b) non uniform layer of $8 \mathrm{~mm}$ near ground end, near energized end and in the center of insulator model (c) non uniform layer of $12 \mathrm{~mm}$ near ground end, near energized end and in the center of insulator model.
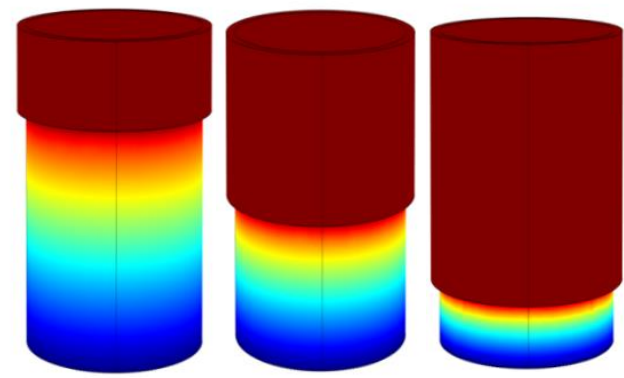

Fig. 12. Electric field distribution along a cylindrical porcelain insulator with pollution layer length

(a) $4 \mathrm{~mm}$ (b) $8 \mathrm{~mm}$ and (c) $12 \mathrm{~mm}$.

It is clearly seen from Figs.14 and 15 that as the pollution position changes, E-field intensity increases. Highest electric field stress was calculated for pollution layer near the energized end. Pollution layer length was kept constant at 4 $\mathrm{mm}$. Based on the simulation results; it was observed that electric field is dependent on 


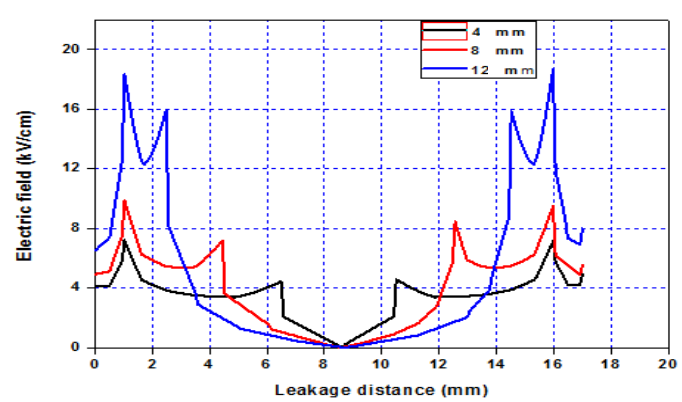

Fig. 13. Electric field distribution along a cylindrical porcelain insulator with different pollution layer length
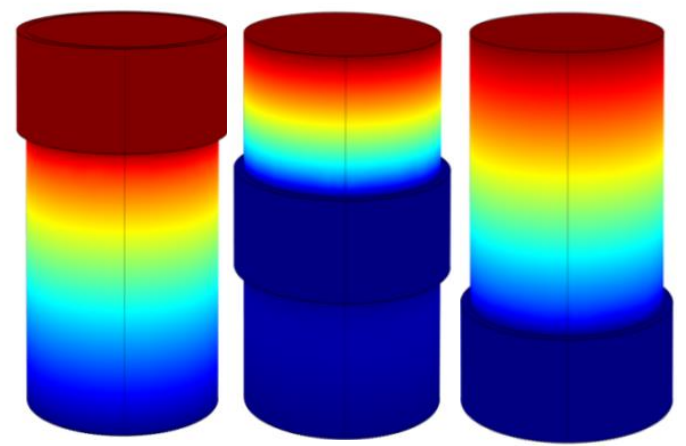

Fig. 14. field distribution along a cylindrical porcelain insulator with pollution position (a) near HV (b) middle and (c) ground.

pollution layer position as well as length. It is shown that the maximum E-field is the lowest when the layer is located in middle position than the cases of layer near the energized and ground ends. It was also observed that increase in E-field intensity is more pronounced with increasing layer length as compared to position. Non-uniform electric field distribution along the insulator surface can affects their flashover characteristics and can damage the insulator in long term[15]. Comparing the experimental results to those given by simulations, it found that better agreement is obtained when pollution layer length increases and the pollution layer lies near the HV end. When the pollution layer lies at the middle or near the ground voltage level is not too high.

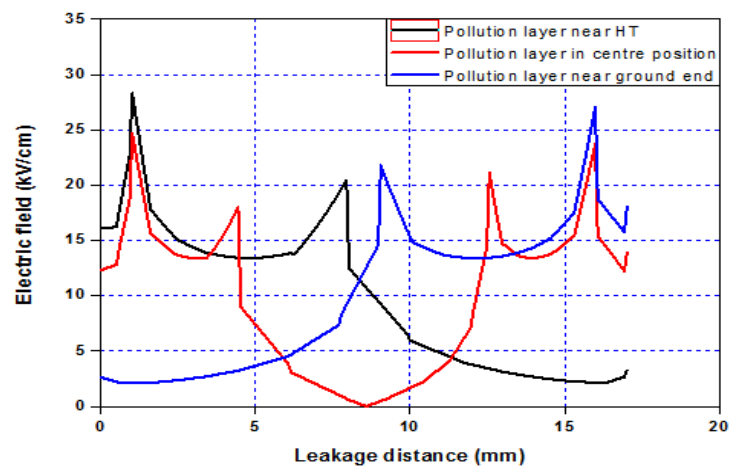

Fig. 15. Electric field distribution along a cylindrical porcelain insulator with different pollution layer position.

\section{CONCLUSIONS}

This paper deals with non-uniform pollution layers deposited on a high-voltage porcelain cylindrical insulator. The influences of the pollution layer conductivity, position and length on the performance the insulator were examined. Experimental tests were made under DC voltage. These were confirmed by simulation results. Various scenarios were studied with: pollution deposited near the energized end, pollution deposited near the ground end and at the middle of insulator surface. This work was made using pollution layers with three different lengths values and conductivities.

Results show that E-field stress has an increase variation trend with the increase of the length of pollution layer. Pollution conductivity does not have a notably impact because it has a neglected effect on the redistribution of electric potential on the surface. On the other side, the flashover voltage and the breakdowns strength are influenced by the pollution layer distribution and the conductivity. This can be caused by the higher leakage current flow which is likely to cause a low voltage flashover. The impact of pollution conductivity may also be limited to accelerating the flashover process. The length of the pollution layer in relation to the inter-electrode distance is the main parameter that influences the flashover operation. Thus it is proposed that the Clean Fog Test Convention could even be propped by a uniform pollution flashover test to get a more detailed and probably more critical scenario from which to draw conclusions about the insulation performance.

Simulations were carried out using Comsol Multiphysics software to assess the influence of pollution layer length, position and conductivity on the E-field distribution along a cylindrical porcelain insulator. It was assumed from simulation results that the E-field is significantly affected by the pollution layer length and position. As the length of the pollution layer increases and lies near the energized end, the E- field intensity increases. The results of this study may provide important theoretical basis for the design and selection of the suitable insulators for polluted area.

\section{REFERENCES}

1. Belhouchet K, Bayadi A, Bendib ME. Artificial neural networks and genetic algorithm modelling and identification of arc parameter in insulators flashover voltage and leakage current. International Journal of Computer Aided Engineering and Technology. 2019;11(1),1-13.

https://doi.org/10.1504/IJCAET.2019.096708.

2. Cigré technical brochure $\mathrm{n}^{\circ} 158$, Working Group 33.13, Polluted insulators: A Review of Current Knowledge. June 2000.

3. Gorur R, Olsen R. Prediction of flashover voltage of insulators using low voltage surface resistance measurement. Power System Engineering Research 
Center, Final Project Report, Arizona State University, 2006.

4. Sahli Z, Mekhaldi A, Boudissa R, Boudrahem S. Prediction parameters of dimensioning of insulators under non-uniform contaminated conditions by multiple regression analysis. Electrical Power System Research. 2011;81(4):821-829. https://doi.org/10.1016/j.epsr.2010.11.017

5. Rizk FAM. Mathematical Models for Pollution Flashover. Electra. 1981;78:71 - 103.

6. Boeme H, Obenhaus F. Pollution flashover tests on insulators in the laboratory and in systems and the model concept of creepage -path flashover. CIGRE. 1966;11: 407.

7. Alston LL, Zoledziowski S. Growth of discharges on polluted insulation. Proc. IEE. 1963; 110(7): 1260 1266.

8. Wilkins R. Flashover voltage of HV insulators with uniform surface pollution film. Proc. IEE. 1969; 116(3): 457 - 465.

9. Belhouchet K, Bayadi A, Belhouchet H, Romero M. Improvement of mechanical and dielectric properties of porcelain insulators using economic raw materials. Boletín de la Sociedad Española de Cerámica y Vidrio. 2019; 58(1):28-37. https://doi.org/10.1016/j.bsecv.2018.05.004

10. Slama ME, Beroual A, Hadi H. Influence of the linear non-uniformity of pollution layer on the insulator flashover under impulse voltage - estimation of the effective pollution thickness. IEEE Trans. Dielectr. Electr. Insul. 2011;18(2):384-392. https://doi.org/10.1109/TDEI.2011.5739441

11. Boudissa R, Djafri S, Belaicha R. Effect of insulator shape on surface discharges and flashover under polluted conditions. IEEE Trans. Dielectr. Electr. Insul. 2005;12(3):429-437. https://doi.org/10.1109/TDEI.2005.1453447

12. Douar MA, Mekhaldi A, Bouzidi MC. Flashover process and frequency analysis of the leakage current on insulator model under non-uniform pollution conditions. IEEE Trans. Dielectr. Electr. Insul. 2010;17(4):1284-1297. https://doi.org/10.1109/TDEI.2010.5539701

13. Ahmed A, Singer H, Mukherjee PK. A numerical model using surface charges for the calculation of electric fields and leakage currents on polluted insulator surfaces. Annual report Conference on Electrical Insulation and Dielectric Phenomena. 1998;1:116-119.

14. Moreno VM, Gorur RS. Impact of corona on the long-term performance of non-ceramic insulators. IEEE Transactions on Dielectrics and Electrical Insulation. 2003;10(1):80-95. https://doi.org/10.1109/TDEI.2003.1176565

Received 09.12.2020

Accepted 2021-03-08

Available online 2021-04-01

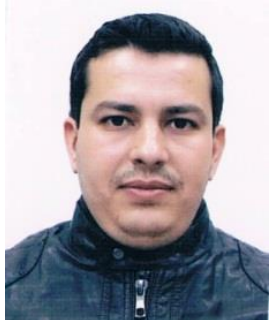

Khaled BELHOUCHET joined M'sila university in 2015 as an Assistant Professor. He obtained then a Ph.D degree from the university of Setif, Algeria in 2020. His research interests are: high voltage engineering, insulation technologies, optimization methods and overvoltage protection. $\mathrm{He}$ is a research member at the Automatic Laboratory of Setif (LAS), University of Setif, Algeria.

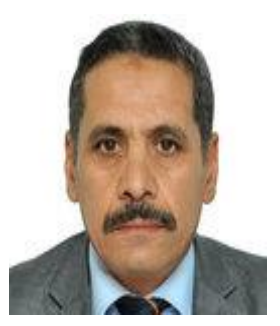

Abdelhafid BAYADI joined Setif institute in 1998 as an Assistant Professor. He obtained then a Ph.D. degree in 2005. In the same year, he was appointed a Senior Lecturer and in 2010, a Professor in electrical engineering. His research interests are power system transients, high voltage engineering, insulation technologies and overvoltage protection. He has coauthored over 140 publications. He is a member of the Steering Committee of the CNHT Conference.

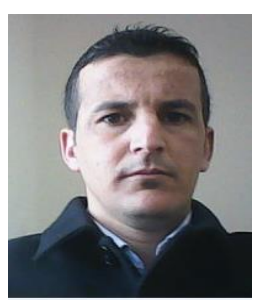

Nadjim ALTI received the engineering degree and Magister degree in electrical engineering from FERHAT ABBAS University of Setif-1 in 2007 and 2012 respectively. $\mathrm{He}$ is currently pursuing the $\mathrm{Ph} . \mathrm{D}$. degree in high voltage engineering in SETIF University. He is an engineer in the Algerian company of Electricity Transmission Network Management (GRTE) since 2010 until today. His research interests are $\mathrm{ZnO}$ surge arrester, high-voltage engine-ering, electric field analysis, high voltage insulation.

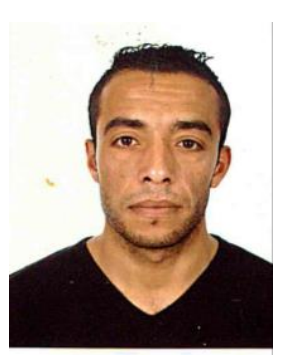

Lyamine OUCHEN obtained the degree of ingénieur d'état In electrical engineering in 2006. The degree of magister in electrical engineering in 2010 from the university of Setif. He obtained the Ph.D. degree in high voltage engineering in 2020. His research interests are in power system modeling and simulation, power system transients, high voltage engineering, insulation systems, and power system overvoltage protection. 